\title{
Do Aphid Colonies Amplify their Emission of Alarm Pheromone?
}

\author{
Eduardo Hatano • Grit Kunert • Stefan Bartram • \\ Wilhelm Boland • Jonathan Gershenzon • \\ Wolfgang W. Weisser
}

Received: 8 April 2008 /Accepted: 21 July 2008 / Published online: 14 August 2008

(C) The Author(s) 2008

\begin{abstract}
When aphids are attacked by natural enemies, they emit alarm pheromone to alert conspecifics. For most aphids tested, $(E)$ - $\beta$-farnesene (EBF) is the main, or only, constituent of the alarm pheromone. In response to alarm pheromone, alerted aphids drop off the plant, walk away, or attempt to elude predators. However, under natural conditions, EBF concentration might be low due to the low amounts emitted, to rapid air movement, or to oxidative degradation. To ensure that conspecifics are warned, aphids might conceivably amplify the alarm signal by emitting EBF in response to EBF emitted by other aphids. To examine whether such amplification occurs, we synthesized deuterated EBF (DEBF), which allowed us to differentiate between applied and aphid-derived chemical. Colonies of Acyrthosiphon pisum were treated with DEBF, and headspace volatiles were collected and analyzed for evidence of aphid-derived EBF. No aphid-derived EBF was detected, suggesting that amplification of the alarm signal does not occur. We discuss the disadvantages of alarm signal reinforcement.
\end{abstract}

This paper and the preceding paper by Verheggen et al. on the same topic were received and processed essentially simultaneously.

E. Hatano $\cdot$ W. W. Weisser $(\bowtie)$

Institute of Ecology, Friedrich-Schiller University,

Dornburger str. 159,

07743 Jena, Germany

e-mail: wolfgang.weisser@uni-jena.de

G. Kunert $\cdot$ S. Bartram $\cdot$ W. Boland $\cdot$ J. Gershenzon

Max Planck Institute for Chemical Ecology,

Hans-Knöll str. 8,

07745 Jena, Germany
Keywords Aphid Alarm Pheromone · $(E)$ - $\beta$-farnesene . Pea Aphid · Acyrthosiphon pisum · Synthesis .

Deuterium labeling

\section{Introduction}

Aphids (Homoptera: Aphididae) are attacked by many different predatory insects and have evolved an efficient defense behavior. When disturbed, they release cornicle droplets that contain a mixture of triglycerides and alarm pheromones (Nault et al. 1973).

The alarm pheromones of many aphid species are, in most cases, single terpenes or mixtures of terpenes (Pickett and Glinwood 2007). For some species, such as the pea aphid, Acyrthosiphon pisum, the sesquiterpene (E)- $\beta$ farnesene (EBF) is the only compound in the alarm pheromone (Francis et al. 2005). The amounts of EBF emitted by individual pea aphids are small, and this may be exacerbated by chemical oxidation or the concentration of the pheromone being diluted rapidly by air movement. Few studies have attempted to investigate emission dynamics of aphid alarm pheromone (Schwartzberg et al. 2008). In particular, it is unclear whether the emission is confined to the attacked aphid or whether the signal is reinforced by members of the colony. The emission of alarm pheromone by aphids that perceive the chemical, but are not attacked, would amplify the signal and presumably warn more individuals in a colony. However, such amplified emission would also expose inconspicuous aphids to natural enemies or unnecessarily alert aphids that are not at risk.

In this paper, we report on a series of experiments in which we use a deuterated $(E)$ - $\beta$-farnesene derivative 


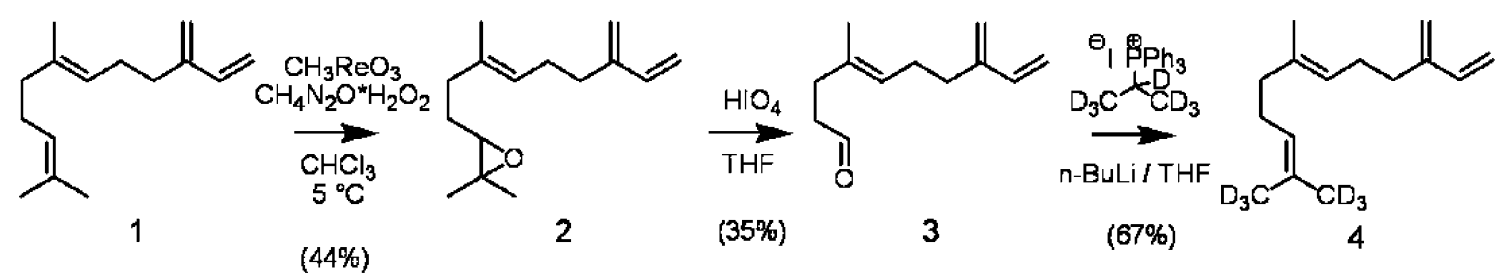

Fig. 1 Synthesis of $[12,12,12,13,13,13]-{ }^{2} \mathrm{H}_{6}-(E)-\beta$-farnesene

(DEBF), labeled on the geminal dimethyl group, to investigate signal reinforcement in the pea aphid.

\section{Methods and Materials}

Synthesis of Deuterated EBF Following Cravotto et al. (2004) (Fig. 1), epoxidation of (E)- $\beta$-farnesene (1) (408.70 mg, $2 \mathrm{mmol}$ ), employing methyltrioxorhenium (VII) and urea-hydrogen peroxide adduct in $\mathrm{CHCl}_{3}$ at $5^{\circ} \mathrm{C}$, gave a mixture of mono- and di-oxiranes. The 10,11-epoxy(E)- $\beta$-farnesene (2) $\left(180.3 \mathrm{mg}, 44 \%, R_{\mathrm{f}} 0.48\right)$ was separated on Florisil 100-200 (petroleum ether 40-60/ether 40:1 v/v). As specified by Fielder and Rowan (1994) (Fig. 1), the epoxide 2 was cleaved with periodic acid to give $(E)$ 4-methyl-8-methylenedeca-4,9-dienal (3) (49.1 mg, 35\%, $R_{\mathrm{f}} 0.27$ ), which was purified on silica 60 (petroleum ether $40-60 /$ ether $40: 1 \mathrm{v} / \mathrm{v})$. Wittig reaction of 3 with $\mathrm{d}_{7^{-}}$ isopropyltriphenylphosphonium iodide produced the $\mathrm{d}_{6}-(E)$ $\beta$-farnesene (4) $\left([12,12,12,13,13,13]-{ }^{2} \mathrm{H}_{6}-(E)-\beta\right.$-farnesene; DEBF) (221.60 $\left.\mu \mathrm{g}, 67 \%, R_{\mathrm{f}} 0.60\right)$. Purification of 4 was carried out by flash chromatography on silica gel (silica 60, Merck, Darmstadt, Germany) with pentane. The chemical purity of DEBF after chromatographic purification was $97 \%$ as determined by gas chromatography-mass spectrometry (GC-MS).

NMR Data of Deuterated EBF ${ }^{1} \mathrm{H}$ NMR (500 MHz, $\left.\mathrm{CDCl}_{3}\right): \delta(\mathrm{ppm})=1.53(\mathrm{~s}, 3 \mathrm{H}), 1.89-1.94(\mathrm{~m}, 2 \mathrm{H}), 1.97-$ $2.03(\mathrm{~m}, 2 \mathrm{H}), 2.08-2.19(\mathrm{~m}, 4 \mathrm{H}), 4.92(\mathrm{~d}, J=1.3 \mathrm{~Hz}, 1 \mathrm{H})$, 4.94 (d, $J=1.3 \mathrm{~Hz}, 1 \mathrm{H}), 4.98$ (d, $J=10.8 \mathrm{~Hz}, 1 \mathrm{H}), 5.03$ (t, $J=6.8 \mathrm{~Hz}, 1 \mathrm{H}), 5.09$ (tq, $J=6.8,1.0 \mathrm{~Hz}, 1 \mathrm{H}), 5.17$ (d, $J=$ $17.7 \mathrm{~Hz}, 1 \mathrm{H}), 6.31$ (dd, $J=17.7,10.8 \mathrm{~Hz}, 1 \mathrm{H})$.

Aphid Lines We used a red clone (BP) of the pea aphid, $A$. pisum, maintained on Vicia faba plants in controlled conditions at $20^{\circ} \mathrm{C}, 16 \mathrm{~L} / 8 \mathrm{D}$ photoperiod, and approximately $75 \%$ RH. For experiments, aphid lines descended from a single founder were established (Kunert et al. 2005).

Experiment 1: DEBF and Aphid Behavior Three groups of 15 apterous adults of the same line were transferred to three plants and covered with cellophane bags $(18.8 \times 39 \mathrm{~cm}, N=$ 12 lines). A piece of filter paper, to which DEBF, EBF (both $1 \mu \mathrm{g}$ in $3 \mu \mathrm{l}$ hexane), or hexane (3 $\mu \mathrm{l})$ was applied, was placed inside the bags. The solutions were applied three times per day over $5 \mathrm{~d}$. After the first application of each solution, the number of pea aphids walking was counted for $5 \mathrm{~min}$. At the end of the experiment, mothers were counted and removed, and nymphs left for four more days on plants. Nymphs were then frozen and scored as winged or apterous morphs.

Experiment 2: $D E B F$ and EBF Release For volatile collection, two groups of 15 third/fourth instars, of the same line, were transferred to two plants $(N=13$ lines $)$ and placed in glass chambers (modified 1-L beaker). Teflon plates were placed around the base of the plant, keeping the soil out of
Fig. 2 Percentage of winged offspring produced by adult pea aphids and number of pea aphid mothers walking after exposure to hexane, $(E)-\beta$ farnesene $(E B F)$ or deuterated $(E)$ - $\beta$-farnesene $(D E B F)$. The bars show the mean value $\pm \mathrm{SE}$

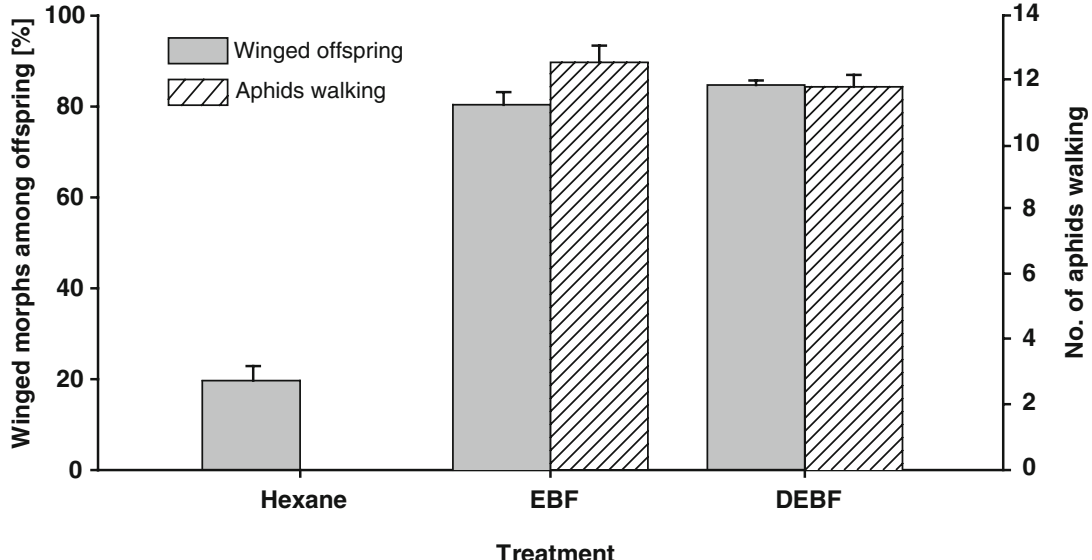


the collection system. Two openings $(\varnothing=1 \mathrm{~cm})$ were present on top of the chamber: one provided air $\left(2 \mathrm{~L} \mathrm{~min}^{-1}\right)$ filtered through active charcoal, and the other held a filter paper to which either DEBF ( $1 \mu \mathrm{g}$ in $3 \mu \mathrm{l}$ hexane) or hexane (3 $\mu$ l) was applied. The chambers had an additional opening $3 \mathrm{~cm}$ from the rim holding a Super-Q filter (80/ 100 mesh; Alltech, Deerfield, IL, USA) connected to an air pump $\left(1 \mathrm{~L} \mathrm{~min}^{-1}\right)$. With this set-up, six plants (three lines) could be tested simultaneously.

Volatile Analysis Super Q filters were eluted with $140 \mu 1$ of dichloromethane and analyzed by GC-MS on a DB$5 \mathrm{MS}(\mathrm{J} \& \mathrm{~W})$ column. For analysis, the column oven was kept at $60^{\circ} \mathrm{C}$ for $2 \mathrm{~min}$., increased to $180^{\circ} \mathrm{C}$ at $5^{\circ} \mathrm{C} \mathrm{min}^{-1}$, and then increased at $60^{\circ} \mathrm{C} \mathrm{L} \mathrm{m^{-1 }}$ until $300^{\circ} \mathrm{C}$. Mass spectra from each peak were compared to those in the NIST and Wiley libraries for tentative peak identification. An internal standard of (E)- $\beta$-caryophyllene (400 $\mathrm{ng}$ in $30 \mu \mathrm{l}$ of $\mathrm{CH}_{2} \mathrm{Cl}_{2}$ ) was added to all samples as an internal standard.

Statistical Analyses The number of aphids walking was analyzed by analysis of variance (ANOVA). Wing induction was analyzed by a generalized linear model $(\mathrm{glm})$ with a quasibinomial error structure. The aphid lines and number of nymphs produced in each replicate were included in the model, which was then simplified by removing non-significant variables or interactions, and accepted after an ANOVA $(P>$ 0.05; Crawley 2007). The survival of the mothers was analyzed with a glm using a Poisson error structure and simplified as described above. Data were analyzed with $\mathrm{R}$ software 2.6.0 (2007) and are presented as mean \pm SE.

\section{Results and Discussion}

In experiment 1, there was no significant difference among treatments in the mean number of adult pea aphids that survived (hexane $=13.75 \pm 0.52 ; \mathrm{EBF}=17.83 \pm 0.44 ; \mathrm{DEBF}=$ $13.58 \pm 0.47 ; t=1.317 ; P=0.197 ; N=36$ ). In both EBF and DEBF treatments, the proportion of winged morphs among aphid offspring was higher than in the hexane treatment (Fig. $2 ; t=15.075 ; P<0.001, N=36$ ). The number of aphids that responded to treatment by walking did not differ between EBF and DEBF (Fig. 2, $t=-1.542, P=0.152, N=$ 36 ); no walking responses were observed in the hexane treatment (Fig. 2, $t=27.211, P<0.001, N=36$ ).

In experiment 2 , aphids started dispersing after DEBF application, but there was no measurable emission of endogenous alarm pheromone, suggesting that only attacked aphids emit EBF. Given the amounts of DEBF applied and re-collected, we estimated that the minimum amount of EBF detected by our experimental system was about $30 \mathrm{ng}$, an amount equivalent to that typically released by two to three third/fourth instars (Schwartzberg et al. 2008). Therefore, because we used colonies of 30 aphids, no more than $10 \%$ of the individuals tested, if any, could have responded by emitting their own EBF.

While signal amplification would have the advantage of alerting more aphids in the colony, it also has disadvantages. For example, it is thought that aphids may use the frequency of alarm pheromone perception as a measure of danger. Experiments with predators that induce alarm pheromone release and synthetic EBF, respectively, have shown that the proportion of winged offspring is related to the number of aphids consumed and the frequency of application of EBF (Kunert et al. 2005). Signal amplification would preclude aphids from employing the frequency of alarm pheromone release as a measure of the severity of an attack. Additionally, some natural enemies use EBF to detect their prey (Acar et al. 2001; Beale et al. 2006), and amplification of the signal would increase the danger of predator attraction.

Acknowledgments We are grateful to Ingrid Jakobi for rearing the aphids, Michael Reichelt for assisting with the GC-MS, Doreen Schachtschabel for helping with the synthesis of DEBF, Efthymia Kazantzidou for assisting with volatile collection, Emily Wheeler for valuable editorial comments, and the Max-Planck-Gesellschaft, International Max Planck Research School (IMPRS) for financial support.

Open Access This article is distributed under the terms of the Creative Commons Attribution Noncommercial License which permits any noncommercial use, distribution, and reproduction in any medium, provided the original author(s) and source are credited.

\section{References}

Acar, E. B., Medina, J. C., Lee, M. L., and Booth, G. M. 2001. Olfactory behavior of convergent lady beetles (Coleoptera: Coccinellidae) to alarm pheromone of green peach aphid (Hemiptera: Aphididae). Can. Entomol. 133:3389-397.

Beale, M. H., Birkett, M. A., Bruce, T. J. A., Chamberlain, K., Field, L. M., Huttly, A. K., Martin, J. L., Parker, R., Phillips, A. L., Pickett, J. A., Prosser, I. M., Shewry, P. R., SMART, L. E., WADHAMS, L. J., WoODCOCK, C. M., and ZhANG, Y. H. 2006. Aphid alarm pheromone produced by transgenic plants affects aphid and parasitoid behavior. Proc. Natl. Acad. Sci. USA 103:10509-10513.

Cravotto, G., Balliano, G., Robaldo, B., Oliaro-Bosso, S., CHIMICHI, S., and BocCALINI, M. 2004. Farnesyloxycoumarins, a new class of squalene-hopene cyclase inhibitors. Bioorg. Med. Chem. Lett. 14:1931-1934.

Crawley, M. J. 2007. The R Book. p. 950. Wiley, Chichester, England. FIELDER, S., and RowAN, D. D. 1994. The synthesis of d(6)-alphafarnesene. J. Labelled Comp. Rad. 34:1075-1085. 
Francis, F., Vandermoten, S., Verheggen, F., Lognay, G., and HAUBRUGE, E. 2005. Is the (E)-beta-farnesene only volatile terpenoid in aphids? J. Appl. Entomol. 129:16-11.

Kunert, G., Otto, S., Rose, U. S. R., Gershenzon, J., and WEISSER, W. W. 2005. Alarm pheromone mediates production of winged dispersal morphs in aphids. Ecol. Lett. 8:596-603.

NAUlt, L. R., EdWARdS, L. J., and Styer, W. E. 1973. Aphid alarm pheromones: secretion and reception. Environ. Entomol. 2:101-105.
Pickett, J. A., and Glinwood, R. 2007. Chemical ecology, pp. 255260, in H.F. Van Emden, and R.H. Harrington (eds.). Aphids as Crop PestsCABI, Wallingford, Oxfordshire.

SchwartzberG, E. G., Kunert, G., Stephan, C., David, A., Röse, U. S. R., Gershenzon, J., Boland, W., and Weisser, W. W. 2008. Real-time analysis of alarm pheromone emission by the pea aphid (Acyrthosiphon pisum) under predation. J. Chem. Ecol. $34: 76-81$. 